\title{
Ação coletiva promovida por inovações tecnológicas: o caso das ONGs brasileira e o Movimento Software Livre*
}

\author{
Viviani Corrêa Teixeira \\ Universidade Federal de Santa Catarina, Florianopolis, Brasil. \\ Email: vivi_teixeira@hotmail.com
}

Resumo: O avanço técnico gerou disparidades ligadas ao campo da informática, algumas empresas aprisionaram o conhecimento através de senhas, licenças e direitos autorais, induzindo a sociedade civil a ficar refém desse processo de exploração comercial e criando uma divisão entre a comunidade de técnicos ligados a computação. Surge o Movimento Software Livre-MSL, em prol da criação, uso e difusão de softwares alternativos e cooperativos, uma nova forma de ação coletiva que visa romper com o sistema econômico vigente utilizando-se do potencial das redes, principalmente da Internet, pois teve sua divulgação e propagação através da Internet por meio da cooperação mútua entre profissionais ligados a informática e alcançou vários segmentos da sociedade civil. Partindo dessas considerações, esse artigo apresenta resultados de uma pesquisa feita com algumas Organizações Não Governamentais-ONGs brasileiras, sobre as contribuições do MSL para a adesão, implementação e migração dos softwares livres por estas ONGs. ONGs.

Palavras-chave: Ação coletiva, Movimentos sociais, Tecnologia, Internet,

\section{La acción colectiva promovida por las innovaciones tecnológicas: el caso de las organizaciones no gubernamentales de Brasil y el Movimiento de Software Libre}

Resumen: Los avances técnicos han dado lugar a diferencias relacionadas con el ámbito de la tecnología de la información; algunas empresas están atrapados por el conocimiento de las contraseñas, las licencias y derechos de autor, lo que condujo a la sociedad civil a ser rehén de este proceso de explotación comercial y a la creación de una división en la comunidad de técnicos en computación. Surge el movimiento del software libre, MSL, para el establecimiento, uso y difusión de programas alternativos y de colaboración, una nueva forma de acción colectiva que pretende romper con el sistema económico imperante, a partir del potencial de las redes, especialmente de Internet, pues tiene su difusión y propagación a través de Internet mediante la cooperación mutua entre los profesionales que trabajan en tecnologías de la información y ha llegado a varios segmentos de la sociedad civil. A partir de estas consideraciones, este trabajo presenta los resultados de una encuesta de algunas organizaciones no gubernamentales-ONG** Brasil, sobre contribuciones al MSL para la adhesión, la aplicación y migración de 
software libre por estas ONG.

Palabras clave: Acción Colectiva, Movimientos Sociales, Tecnología, Internet, ONGs.

\title{
Collective action promoted by technological innovations: the case of Brazilian NGOs and the Free Software
}

\begin{abstract}
The technical advances have created disparities related to the field of information technology; some companies are trapped by the knowledge of passwords, licenses and copyrights, prompting the civil society to be held hostage to this process of commercial exploitation and creating a division among the community of technicians on the computer. Arises the Free Software MovementFSM, for the establishment, use and dissemination of alternative and collaborative software, a new form of collective action that aims to break with the prevailing economic system, using the potential of networks, especially the Internet, because it has its dissemination and spreading across Internet by means of mutual cooperation between professionals engaged in information technology and has achieved several segments of civil society. From these considerations, this paper presents results from a survey of some Non-Governmental Organizations-NGOs in Brazil, about the contributions of FSM for accession, implementation and migration of free software by these NGOs.
\end{abstract} NGOs.

Key words: Collective Action, Social Movements, Technology, Internet,

\section{Apresentação: \\ a sociedade e as delimitações no uso de alguns softwares}

Quando falamos em comunicação, não podemos deixar de falar mais especificamente dos computadores, que hoje, com a conexão à Internet se caracterizam como um dos meios de comunicação e informação mais eficientes do planeta. Com frequência ouvimos o termo "rede mundial de computadores”, essa expressão significa que os computadores estão conectados pela rede Internet, e essa conexão proporciona informação e comunicação constante e em tempo real de qualquer parte do mundo ${ }^{1}$. O computador é composto de hardware e software, hardware é a parte física, isto é, a máquina, software é uma sentença escrita em uma linguagem computável, para a qual existe uma máquina (computável) capaz de interpretá-la. A sentença (o software) é composta por uma sequência de instruções (comandos) e declarações de dados, armazenável em meio digital.

De acordo com a Lei 9.609/98, artigo Art. $1^{0}$ :

Programa de computador é a expressão de um conjunto organizado de instruções em linguagem natural ou codificada, contida em suporte físico de qualquer natureza, de emprego necessário em máquinas automáticas de tratamento da informação, dispositivos, instrumen- 
tos ou equipamentos periféricos, baseados em técnica digital ou análoga, para fazê-los funcionar de modo e para fins determinados (INPI: 2008).

Hardware e Software não funcionam separadas, e nos primeiros computadores dificilmente eram vendidos separados, porque a Microsoft produzia as máquinas e também o Sistema Operacional, com isso ela foi crescendo cada vez mais e tomando proporções enormes, cresceu tanto que dominou o comércio mundial de software. Atualmente tanto o mercado como o Estado passaram a ter que cumprir os contratos pré-estabelecidos de compra e uso dos produtos das corporações Microsoft.

O software rotulado como proprietário é de posse única e de manutenção exclusiva, exceto no caso dos softwares piratas ${ }^{2}$. Todo adquirente é obrigado a ter uma senha de acesso ao sistema operacional, impossibilitando assim a cópia ou a disseminação dos programas por usuários não proprietários, pois cada máquina possui uma senha ${ }^{3}$ requisitada na hora da instalação. No caso dos softwares piratas, poderíamos dizer que são clones dos originais, instalados em máquinas diferentes, mas com o mesmo número de série, e, no caso de inspeção legal, ou por parte de instituições responsáveis pela compra das licenças, seriam classificados como ilegais. O monopólio dos softwares proprietários, principalmente da Microsoft, tem tornado o uso desses softwares economicamente inviável para muitos usuários de computadores ${ }^{4}$, isso induz muitos usuários a procurar outras alternativas, menos restritas e economicamente viáveis, tais como os softwares livre.

\section{Inovação tecnológica: o software livre no mundo e no Brasil}

No Brasil as iniciativas para o uso dos softwares livre partem das empresas privadas, do Estado e também de algumas organizações não governamentais. As principais entidades que fomentam o uso de software livre no Brasil são a Conectiva Linux, fundada em 1995, com sede em Curitiba-PR, representa a versão brasileira do sistema operacional GNU/ Linux; OpenOffice.org, que é um projeto de código aberto composto por um pacote de ferramentas, como processador de textos, planilha de cálculos, um editor HTML, um editor vetorial e um editor de apresentações compatíveis tanto com o Linux como com o Windows (openoffice.org, 2002).

O Debian-Br, que é a distribuição GNU/Linux em todo mundo e tem como característica a universalidade. Esse projeto visa desenvolver um sistema operacional livre que possa ser usado em qualquer parte do mundo por qualquer pessoa; o Kurumin Linux é uma distribuição brasileira do sistema operacional baseado no Knoppix (o qual se baseia no Debian). Sua principal característica é o tamanho pequeno, podendo ser instalado 
até em computadores mais antigos, possibilitando rodá-lo em computadores como o Pentium 100. O CIPSGA - Comitê de Incentivo à Produção de Software GNU e Alternativo, criado em 1999 por Djalma Valois, um profissional oriundo da informática, que pode ser considerado um representante das organizações que suportam o desenvolvimento do software livre. O Projeto Software Livre RS, iniciado no ano de 2000, em Porto Alegre, encontra-se na linha das organizações que apoiam e fomentam o uso de alternativas livres, tratando-se de uma organização não governamental que reúne diversas instituições públicas e privadas do Estado do Rio Grande do Sul, como poder público, desenvolvedores, empresários, grupos de usuários, universidades e ONGs.

\section{Uso de software livre: a experiência de algumas ONGs brasileiras}

Nem sempre os softwares proprietários estão preparados para atender as necessidades dos indivíduos ou do mercado. Quando Linus Torvalds necessitou de uma versão do Unix para rodar em um PC e não encontrou, tentou achar a solução para o seu problema. Essa tentativa auxiliou na construção de um outro sistema operacional que resultou no Linux. Eric Allman ${ }^{5}$ precisava distribuir e-mails para vários endereços em Berkeley de uma forma eficiente, essa necessidade resultou no Sendmail. Como essas iniciativas, inúmeras são as motivações que levam à adesão ou construção de um aplicativo de computador.

Ao indagar as ONG sobre o uso de software livre, obtivemos o seguinte resultado:

Tabela 1 - Uso de software livre ou código fonte aberto pelas ONGs

\begin{tabular}{|l|c|}
\hline Uso de software livre pela ONG & Número de ONGs \\
\hline Usam software livre & 25 \\
\hline Não usam software livre & 29 \\
\hline Usam os dois tipos & 01 \\
\hline
\end{tabular}

Fonte: Dados da autora, organizado pela autora, 2008. 


\section{Gráfico 1}

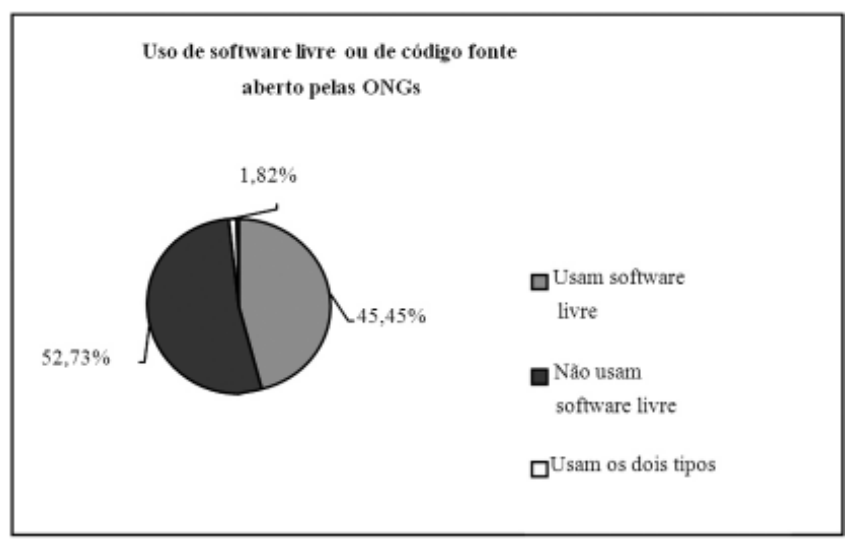

Fonte: Organizado pela autora, 2008.

Das 55 entidades (ONGs) que responderam ao questionário $(45,45 \%)$ estão imersas nesse processo, ou seja, utilizam softwares livre, e $(52,73 \%)$ não usam softwares livre no seu cotidiano ou em suas atividades. Embora nossa pergunta tenha sido em torno dos softwares livre, deixamos um espaço em aberto para as entidades se expressarem. Nesse espaço houve uma entidade que respondeu que usava os dois tipos $(1,82 \%)$ de software (o livre e o proprietário) na execução das suas atividades.

A diferença entre as entidades que usam software livre e as que não usam é de quatro entidades. Isso demonstra que, apesar da maioria delas ainda não estar usando os softwares livre, a diferença não chega a ser suficientemente significativa a ponto de causar uma disparidade. Muito pelo contrário, representa um ponto positivo considerando que esse processo de migração ainda vem tentando construir uma clientela fiel e lutando para obter espaços.

Nessa pergunta, também foi inquirida a data de inicio do uso dos softwares livre pelas ONGs. Das 25 entidades que afirmaram usar software livre, 21 delas responderam desde quando usam software livre. No quadro abaixo poderemos observar a distribuição das entidades por ano de início de uso dos softwares livre: 
Quadro 1 - Data aproximada do início do uso de software livre pelas entidades, divididos em períodos de 4, 5 e 3 anos

\begin{tabular}{|c|c|}
\hline Ano & N $^{\circ}$ de ONGs \\
\hline 1993 a 1997 & 02 \\
\hline 1998 a 2003 & 05 \\
\hline 2004 a 2007 & 14 \\
\hline Total & $\mathbf{2 1}$ \\
\hline
\end{tabular}

Fonte: Dados da autora, 2008.

Conforme estes dados podemos observar que a relação que as ONGs tem com os softwares livre é considerável, mas é relativamente recente, principalmente levando-se em consideração que a data de início da trajetória da informática no Brasil se deu nos anos 60 e que o processo de migração das ONGs para os softwares livre não chega a 15 anos.

Entre os anos de 1993 e o ano 1997, duas entidades adotaram software livre em suas atividades. Uma foi a ASSESSOAR, de Francisco Beltrão-PR no ano de 1997. Essa entidade atua na formação política e produtiva tendo como público alvo pequenos agricultores. A outra (em 1993) foi o Movimento Infanto Juvenil de Reinvindicação-MIRIM-BRASIL de Recife-PE, essa entidade tem como público alvo crianças, adolescentes e jovens e atua na área de direitos humanos, direitos de acordo ao ECA- Estatuto da Criança e do Adolescente. De 1998 a 2003 tivemos registros de 5 entidades que passaram a usar software livre em suas atividades, o período no qual foram registradas mais adesões foi de 2004 até novembro de 2007, com 14 entidades aderindo a eles.

\section{O que motiva uma entidade a usar software livre?}

Perguntamos para as ONGs, quais razões as incentivaram ou incentivariam a usar os softwares livre, obtivemos o seguinte quadro de respostas:

Tabela 2 - Razão para a entidade utilizar software livre ou software de código fonte aberto

\begin{tabular}{|l|c|}
\hline \multicolumn{1}{|c|}{ Razão } & Número de vezes citadas \\
\hline Econômica & 15 \\
\hline Política & 14 \\
\hline Tecnológica & 12 \\
\hline Social & 11 \\
\hline Educativa & 07 \\
\hline
\end{tabular}

Fonte: Dados da autora, organizado pela autora, 2008. 


\section{Gráfico 2}

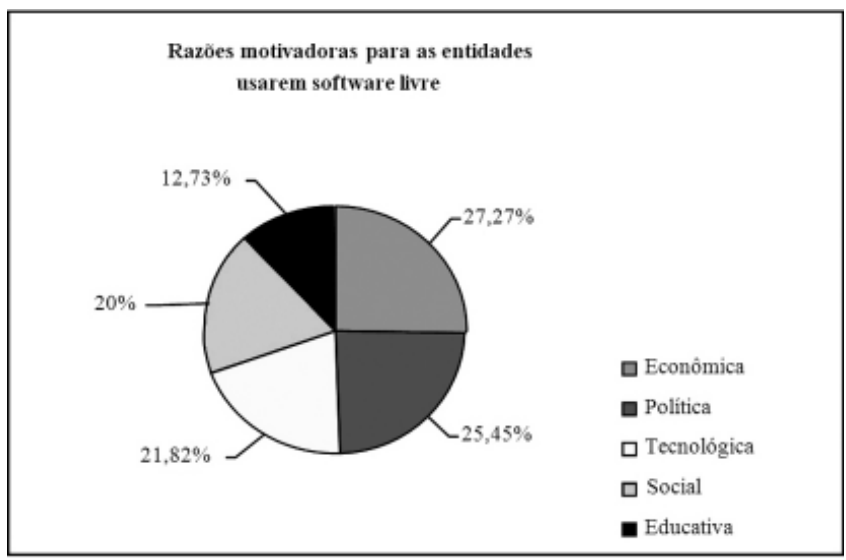

Fonte: Organizado pela autora, 2008.

Das 55 entidades que responderam ao questionário, 23 associadas apontaram múltiplas razões pelas quais se motivaram a usar software livre, as respostas se dividem entre as seis proposições colocadas na pergunta ${ }^{6}$. Entre todas as opções oferecidas, a alternativa mais citada como agente para o uso de software livre, foi à razão econômica (27,27\%), em segundo lugar encontra-se a razão política (25,45\%), a razão tecnológica em terceiro lugar (21,82\%), em quarto lugar aparece a razão social (20\%) e, por último a que menos apareceu foi a razão educativa (12,73\%).

Conforme estes dados, podemos observar que os códigos sendo abertos, a comunidade técnica tem autonomia para se movimentar livremente na confecção, manutenção e arranjo de seus próprios programas, através de soluções individuais ou livremente compartilhadas sem muito desprendimento de investimento financeiro. Poderíamos dizer que o software livre dá quase total independência em relação ao fornecedor de soluções, pois a partir do momento que o código fonte é liberado, milhões de especialistas podem ajudar ${ }^{7}$ nas soluções que os softwares necessitam, seja via rede ou presencial ${ }^{8}$.

Ideologicamente a construção e o uso de software livre está imerso em um complexo mosaico de idéias. Elas podem variar desde a luta pela liberdade para poder se exercer a manutenção técnica dos softwares; contra hegemonia das grandes empresas produtoras de softwares ou, até mesmo, vontade que o conhecimento seja difundido e repassado e que todos tenham acesso a ele. Além da comunidade técnica e estudiosos interessados no tema software livre, estão na luta pela sua adoção, uso ou intercedendo pelas licenças livres e pela liberdade do software: movimentos sociais, ONGs, representantes do Estado, intelectuais, anarquistas, capitalistas, co- 
munistas, libertários de direita, socialistas, pessoas sem inserção política, sindicalistas, políticos, estudantes, micro-empresários, mega-corporações, artistas etc.

\section{Ação coletiva: o Movimento Software Livre}

No intuito de fazer com que a comunidade científica e a sociedade civil comece a aderir aos softwares livre (no início, mais conhecidos como Sistema Operacional GNU/Linux), surge uma discussão liderada por Richard Matthew Stallman ${ }^{9}$ e um grupo sui generis de indivíduos que compartilhavam o mesmo objetivo, sacudir a comunidade científica, a sociedade civil e alguns segmentos do Estado a migrarem para o uso de software livre, abandonar as licenças e a hegemonia do Sistema Operacional Windows de propriedade única e exclusiva da empresa Microsoft.

As discussões, trocas de informações e ações coletivas em torno do software livre desencadearam um movimento a favor da utilização do Sistema Operacional GNU/Linux e, em conseqüência, contra a dominação do Sistema Operacional Windows e seus aplicativos. O Movimento Software Livre (MSL), que responde por esse nome no Brasil, mas em outros lugares no resto do mundo atende por outras denominações como Open Source, FLOSS (Free, Libre and Open-Source Software), FOSS (Free and Open Source Software) e pode ser compreendido como um composto de diferentes ideologias. O MSL teve início na década de 80, paralelamente ao surgimento do Sistema Operacional GNU/LINUX (software livre), espalhouse pela rede mundial de computadores e vem ganhando adeptos no mundo inteiro.

Ainda que o MSL tenha suas origens em torno de uma discussão local, movimentar uma comunidade de técnicos europeus para melhorar um Sistema Operacional, alcançou dimensões globais, servindo como exemplo do poder e do potencial da rede pluridimensional, principalmente da Internet. Pois além do movimento transpor as múltiplas barreiras culturais, sociais e econômicas, se estende ao longo das fronteiras virtuais transformando $^{10}$ a realidade que muitas vezes é imposta por grupos hegemônicos pela falta de informação ou desigualdade econômica.

Podemos dizer que o movimento do software livre ${ }^{11}$ recruta cada vez mais adeptos por se tratar de um movimento, a priori, com características contra hegemônicas, que carrega consigo um conjunto de interessados no tema da autonomia, da justiça econômica, do fortalecimento de sistemas/softwares próprios e capazes de ser auto-suficientes.

De acordo com Sérgio Amadeo da Silveira (2003), o movimento de software livre é a maior expressão da imaginação dissidente de uma sociedade que busca mais do que a sua mercantilização. Trata-se de um movimento baseado no princípio do compartilhamento do conhecimento e na solidariedade praticada pela inteligência coletiva conectada na rede 
mundial de computadores. Sem esquecer as várias apostas que estão inclusas no movimento de fazer com que o mundo digital seja mais democrático, acessível, e que o ativismo que está por trás do movimento, decorre da intenção de combater a hegemonia de alguns grupos e países dominantes dos meios tecnológicos (informática).

Embora o ponto de partida do Movimento Software Livre seja a questão da democratização tecnológica, não somente essa temática está implícita no movimento. Além disso, estão inseridas nos objetivos do movimento, a luta pelo não pagamento de licenças, a adaptação à realidade local de cada máquina ${ }^{12}$, usuários, grupos sociais e tentativa de promover a liberdade de cada país na hora de adquirir um Sistema Operacional ${ }^{13}$ para seus computadores ou programas que facilitem a vida dos indivíduos.

Castells (2005), afirma que o Movimento Software Livre precisa se esforçar mais para fazer o mundo ver por que o software livre é importante. Ele diz que é preciso falar com a sociedade e explicar, mesmo aos que não gostam de computadores, para demonstrar como o software livre é fundamental:

(...) "não se pode esperar que surja um novo Linux ou um novo Killer APP (Programa Aplicativo de Ponta) a cada dia, mas que o mais importante, seria que, cada grupo desenvolva o que necessita e que tudo vá se conectando. Mais do que grandes inovações, são mais importante milhões de pequenas inovações interconectadas e, nesse sentido, o movimento me parece muito forte, muito". (Disponível em: <http://www.softwarelivre.org/news/3697>. Acesso em: 22/02/2005).

\section{Ou como afirma Conceição:}

É um fato que a sociedade mundial atravessa por uma fase nova, uma fase em que as pessoas se vêem cada dia mais envolvidas com a tecnologia. Mas, o que há de mais impressionante nesta fase é o conhecimento sendo compartilhado para que os recursos tecnológicos sejam cada vez mais acessíveis. Este compartilhamento de conhecimento é o que o Movimento Software Livre oferece, dando suporte a uma sociedade coletiva que visa, não a retenção do saber, mas um conhecimento cada vez maior, trazendo benefícios tecnológicos, sociais e culturais para a sociedade mundial (Conceição 2005: 41).

Atualmente o Movimento Software Livre, além de mobilizar a comunidade cientifica/tecnológica no empenho pela liberdade de escolha na confecção dos softwares, tenta conscientizar os usuários de que a migração para um software de código fonte aberto, livre para ser melhorado e adaptado a cada realidade de usuário, pode ser economicamente muito mais viável, transformando o eventual pagamento das licenças (royalties) em dinheiro ou verba poupada que poderá ser usada com outras finalidades, como o fortalecimento de outras políticas de inclusão social/digital: 
O Movimento Software Livre é outro esforço que contribui à inclusão digital. Em primeiro lugar por razões econômicas, na medida em que viabilizará ao usuário o acesso a programas que não teriam possibilidades de comprar e manter-se atualizado em relação aos aplicativos que podem servir ao aumento de eficiência, em toda uma diversidade de atividades, o que pode contribuir decisivamente para a "inclusão digital” (Santos 2005: 3).

As ONGs se mostram cientes do Movimento Software Livre e estão usando os softwares livre, ficando evidente que são simpatizantes ou apoiadoras do mesmo. O movimento surge com a perspectiva de mobilizar e esclarecer a comunidade técnica e outros interessados sobre o uso dos programas livres, mas atualmente é símbolo de outras lutas que vão além da perspectiva técnica, baseando-se numa lógica de liberdades, carrega consigo discussões sobre direitos autorais, socialização do conhecimento, contra- cultura e contra-hegemonia.

Conforme Boaventura de Souza Santos, as lutas de dimensão planetária em defesa de valores humanitários são um patrimônio comum da humanidade:

Trata-se de lutas transnacionais pela proteção e desmercadorização de recursos, entidades, artefatos, ambientes considerados essenciais para as sobrevivência digna da humanidade e cuja a sustentabilidade só pode ser garantida à escala planetária. Pertencem ao patrimônio comum da humanidade, em geral, as lutas ambientais, as lutas pela preservação da Amazônia, da Antártida, da biodiversidade ou dos fundos marinhos e ainda as lutas pela preservação do espaço exterior (Souza Santos 2002: 70).

Nesse sentido, pode-se incluir o desenvolvimento compartilhado do software livre, pois a luta por um sistema de código aberto e irrestrito pode ser uma luta pela globalização contra-hegemônica, uma vez que, devido aos baixos custos, pode possibilitar a inclusão digital de grupos socialmente excluídos da tecnologia da informação:

(...) a organização transnacional de resistência de Estado-nação, regiões, classes ou grupos sociais vitimados pelas trocas desiguais de que se alimentam os localismos globalizantes e os globalismos localizados, usando em seu beneficio as possibilidades de interação transnacional criadas pelo sistema mundial em transição, incluindo as que decorrem da revolução nas tecnologias da informação e comunicação. A resistência consiste em transformar trocas desiguais em trocas de autoridade partilhada, e traduz em lutas contra a exclusão, a inclusão subalterna, a dependência, a desintegração, a despromoção (Ibid: 67).

O Movimento Software Livre não pode ser considerado um movimento revolucionário anti-capitalista ou anti-business, mas sim de 
oposição ao modelo de comércio das indústrias de software proprietários vigente. O MSL não adota regras econômicas ortodoxas como seu único opositor. Ele vai além e questiona princípios até mesmo dos modelos econômicos que giram em torno da informatização e da esfera virtual. Sua premissa é atentar para o fato de que é preciso se opor aos preceitos estabelecidos, buscar e criar alternativas que irão se contrapor a uma hierarquia de valores imposta: ou o usuário passa a ter liberdade ou o proprietário continua tendo ganhos indiretos. O modelo de licença de uso de software livre surgido com o projeto GNU, visa resguardar o direito do usuário à liberdade, não tendo como premissa o benefício econômico do autor ou de quem dele desejar se apossar. O seu valor principal é a liberdade, e o benefício econômico pode ser angariado pela cooperação e socialmente distribuído.

A grande força do software livre está na ação coletiva que move toda uma demanda de pessoas a querer uma nova realidade sem imposições mercadológicas, pressões políticas, aprisionamento do conhecimento e da técnica ou qualquer outro tipo de restrição que segregue alguns grupos e segmentos sociais. O Movimento Software Livre tem sido o principal caminho para a realização desse projeto, sem o qual as premissas do software livre não teriam ganho visibilidade alguma e não conseguiriam alcançar seus propósitos.

Mesmo que a princípio o objetivo do movimento fosse divulgar os softwares livre somente entre os especialistas ligados à informática, seria preciso explicar as funcionalidades dessa nova tecnologia para uma legião de técnicos espalhados pelo mundo todo, depois para os fornecedores e, por último, para os consumidores, mesmo não tendo esse foco inicial, o movimento se difundiu, e atualmente ganhou força devido à colaboração de diversos setores, entre eles as ONGs brasileiras. Caso a sociedade civil não conheça ou não saiba utilizar essa nova ferramenta, a possibilidade de adoção passa a ser irrealizável e as interconexões terão que ir além do caráter tecnológico ou de discussões de cunho econômico.

\section{O Caso das ONGs brasileiras e o Movimento Software Livre}

Os meios de comunicação e informação estão bastante evoluídos e a Internet se apresenta como uma ferramenta fundamental nas atividades cotidianas internas e externas das pessoas, instituições, organizações e demais segmentos da sociedade civil:

Tradicionalmente muitos governos e corporações conseguiam impor medidas contra os interesses coletivos, devido à crença na incapacidade de organização e resistência dos afetados. Contudo, com o uso criativo das tecnologias de informação e comunicação, 
ações específicas e circunstanciadas podem gerar um agregado de peso de forças contrárias de alcance global. Aos indivíduos e coletivos sociais, que outrora se encontravam dispersos ou isolados, é possível concentrar suas ações em prol de uma causa comum, com base nas extensas redes de solidariedade de natureza identitária (Machado 2007a: 264).

É evidente que os movimentos sociais se utilizam também e cada vez mais dessa ferramenta para mobilizar a comunidade ${ }^{14}$ em torno de causas polêmicas ou para requerer a solução de problemas. Os militantes inseridos no Movimento Software Livre também se incluem nesse grupo de ativistas que faz protestos, reivindicações e busca adeptos via rede.

Com base nas considerações de Ribeiro (2000), o Movimento Software Livre é a expressão autêntica desse potencial da rede de transpor fronteias e alcançar diversos territórios, e o grande modelo para a consolidação de soluções compartilhadas diante de questões complexas, a partir da interação multiétnica, multinacional e multicultural. A expansão que o movimento alcançou devido a rede, é a afirmação da possibilidade da Internet consolidar-se também como uma esfera pública planetária, evitando a condição hegemônica de supermercado global ${ }^{15}$, pois desde que se tenha acesso à máquina e à rede Internet, as transações ficam mais fáceis e rápidas.

Ao questionarmos as ONGs sobre seu conhecimento do Movimento Software Livre, obtivemos as seguintes respostas:

Tabela 3 - Número de entidades que conhecem ou não o Movimento Software Livre

\begin{tabular}{|l|c|}
\hline \multicolumn{1}{|c|}{ Alternativa } & Número de entidades \\
\hline Conhecem & 40 \\
\hline Não conhecem & 14 \\
\hline Não Responderam & 1 \\
\hline
\end{tabular}

Fonte: Dados da autora, organizado pela autora, 2008. 


\section{Gráfico 3}

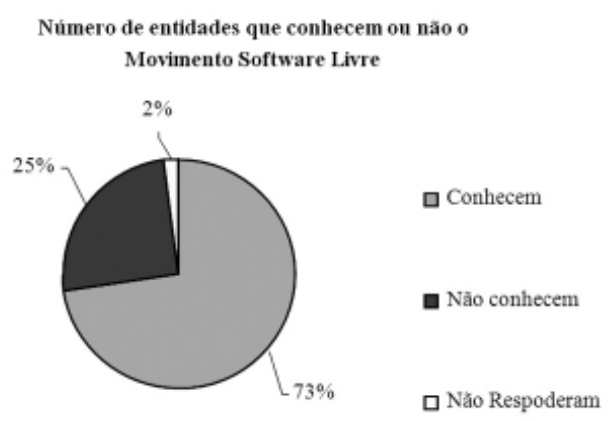

Fonte: Organizado pela autora, 2008.

Conforme os dados expostos na tabela 3 e no gráfico 3, das 55 ONGs que responderam a pesquisa, $40(72,73 \%)$ responderam que conhecem o Movimento Software Livre, ou seja, estão inteiradas do MSL; 14 (25,45\%) responderam que não conhecem o Movimento; e $1(1,82 \%)$ entidade não respondeu à pergunta. De acordo com esses dados, podemos afirmar que a maioria das entidades (ONGs) que participaram da pesquisa estão informadas sobre o Movimento Software Livre.

\section{Como as ONGs brasileiras conheceram ou ouviram falar do Movimento Software Livre?}

Quando questionadas sobre o meio de comunicaçâo ou informação pelo qual as ONGs tiveram conhecimento ou ouviram falar do Movimento Software Livre, as resposta se dividiram entre as oito alternativas propostas ${ }^{16}$ contato pessoal, Internet, livro, movimentos sociais, rádio, revista, televisão, outros: 
Tabela 4-Meios de comunicação ou interação pelos quais as entidades tiveram conhecimento do MSL

\begin{tabular}{|l|c|}
\hline Meios de informação & Número de respostas \\
\hline Internet & 26 \\
\hline Movimentos sociais & 24 \\
\hline Contato pessoal & 13 \\
\hline Revista & 13 \\
\hline Televisão & 6 \\
\hline Rádio & 5 \\
\hline Livro & 5 \\
\hline Outros & 8 \\
\hline
\end{tabular}

Fonte: Dados da autora, organizado pela autora, 2008.

\section{Gráfico 4}

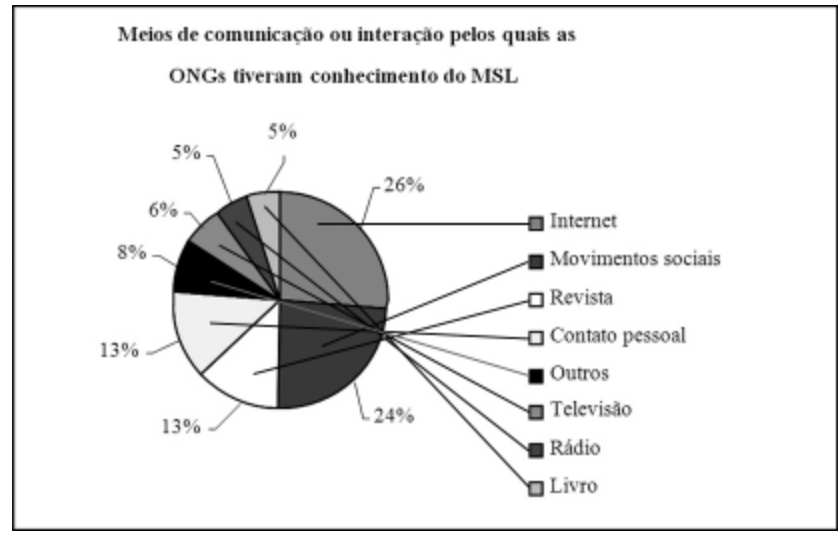

Fonte: Organizado pela autora, 2008.

No primeiro lugar das menções aparece a Internet (26 vezes), representando (26\%) do total das respostas. Em segundo lugar (24\%) aparece à alternativa movimentos sociais. Atualmente, na era da comunicação e informação, consideramos que estes dois meios se retro-alimentam, já que movimentos sociais de todo tipo se aproveitam da flexibilidade da rede para divulgar suas propostas, pois:

A possibilidade de comunicação rápida, barata e de grande alcance faz atualmente da Internet o principal instrumento de articulação e 
comunicação das organizações da sociedade civil, movimentos sociais e grupos de cidadãos. A rede se converteu em um espaço público fundamental para o fortalecimento das demandas dos atores sociais para ampliar o alcance de suas ações e desenvolver estratégias de luta mais eficazes. Agrupando dezenas ou até centenas de organizações de diferentes portes e universos culturais, lingüísticos e identitários diversos, com base na infra-estrutura da rede mundial, elas conseguem agregar eficiente e eficazmente o descontentamento, para gerar amplas e complexas sinergias em ações globais (Machado 2007b: 248-249).

Sejam organizações ecologistas, ideólogos de direita como os de nazismo e racismo, ou os de contra-dominação como o Movimento Software Livre, conseguem maior divulgação e dimensão através da Internet. Embora os movimentos sociais não ajam de forma articulada entre si como alguns militantes esperam ${ }^{17}$, não deixam de divulgar outros movimentos sociais e se comunicar entre eles e demais entidades ${ }^{18}$. Exemplo disso é o Fórum Social Mundial, que reuniu múltiplas entidades da sociedade civil para tratar dos mais diversos temas de interesse da sociedade civil organizada, ONGs, associações e até mesmo algumas esferas do Estado, deixando bem claro que a comunicação existe e pode ser cada vez mais ampliada e melhorada, desde que haja constância.

Em terceiro lugar, empatadas, aparecem as alternativas contato pessoal $^{19}$ (13 vezes) e revista (13 vezes) cada uma representando (13\%) do total das escolhas. As revistas abrangem vários temas, são mais popularizadas, além das revistas especializadas no assunto software livre ${ }^{20}$, que podem ser adquiridas por baixo ou zero custo. Podemos entender que para o conhecimento do Movimento Software Livre as revista e o contato pessoal têm o mesmo poder de difusão das informações e da comunicação.

A alternativa televisão aparece em quinto lugar (6 vezes), representando (6\%) do total das repostas obtidas. As alternativas livro e rádio ficam empatadas em último lugar (5 vezes) citadas, representando (5\%) do total das respostas. Conforme esses dados podemos afirmar que os livros, o rádio e a televisão têm contribuído pouco para a difusão do Movimento Software Livre. Apesar do longo alcance que o rádio e a televisão têm como meios de comunicação e informação ${ }^{21}$, em relação à divulgação de ações coletivas como o Movimento Software Livre eles deixam muito a desejar.

Já os livros nem sempre estão disponíveis e são mais difíceis de ser acessados devido ao seu custo, linguagem técnica e especializada. Se não houver um incentivo à leitura e um entendimento dos temas proposto neles, de nada adiantará ao público leigo no assunto, ler sobre o Movimento Software Livre. É preciso explicar as finalidades tanto do movimento como dos softwares livre de uma maneira menos complexa, coisa que ainda aparece pouco, tanto nos livros acadêmicos como nos livros em geral.

A alternativa outros foi mencionada 8 vezes, representando (8\%) 
do total das respostas. Dentre essas respostas, algumas entidades salientaram quais meios foram estes. O SEDUP teve conhecimento do movimento através de material de software livre e o CEBRAP pela participação em eventos organizados por técnicos da área. Por fim, a entidade Católicas Pelo Direito de Decidir, tomou conhecimento do Movimento Software Livre por meio de jornal impresso. De uma maneira ou de outra as entidades foram informadas da existência do Movimento Software Livre, pois em sua maioria (73\%) conhecem o movimento.

\section{A participação das ONGs no Movimento Software Livre}

Quais ONGs atuam ou militam no Movimento Software Livre e como exercem essa militância ou participação? Das 55 entidades que responderam ao questionário, 9 atuam no Movimento Software Livre, e a forma de participação ou atuação no movimento é bem variada. A entidade IRPAA de Juazeiro-BA declara que "algumas pessoas da equipe colaboram na tradução de textos” e através dessa atitude participa do movimento.

A ESPLAR de Fortaleza-CE vem “procurando ao máximo utilizarse de programas livres”. Ela considera que, com essa atitude, está participando ativamente do movimento. Nessa mesma direção, caminha também a entidade CAMPO do Rio de Janeiro, por desenvolver "parceria e projetos sociais com entidades que atuam com esses softwares e divulgação de informação sobre o assunto junto aos grupos”. Assim como o IBASE, que fica "no apoio e participando de atividades ligadas ao tema como o Fórum Internacional de Software Livre”, que serve exclusivamente para discutir o tópico software livre e as tendências do Movimento Software Livre no mundo.

Com a intenção de difundir o Movimento Software Livre, a entidade ELO-Ligação e Organização de Salvador-BA, atua na "organização de atividades de sensibilização e capacitação sobre o tema”. Nessa tentativa também aparecem as "listas de discussão/fóruns/Casa Brasil”, citada pela entidade Movimento Tortura Nunca Mais, que tem por finalidade discutir e difundir o movimento.

Outras entidades, além da organização de oficinas temáticas ou listas de discussões trabalham de maneira mais pontuais. É o caso da ASSESSOAR, que atua "no âmbito da rede Ecovida, onde contribuímos na elaboração da página e banco de dados interativo todo em software livre e dos movimentos sociais do campo, promovendo oficinas, divulgando na nossa página, apoiando grupos de usuários...”. Ao fornecer trabalho para a rede Ecovida, a ASSESSOAR vai dando visibilidade ao uso de software livre e com isso vai engajando simpatizantes e novos adeptos para o movimento do software livre através de suas atitudes e práticas.

Na mesma perspectiva da ASSESSOAR encontra-se a ABDL, uma entidade com sede em São Paulo que afirma atuar no movimento "partici- 
pando das conferências, seminários, encontros etc., promovendo a sensibilização para a questão nos programa de formação para a ação, como o Redesenvolvimento - Programa de Formação em Redes para o Desenvolvimento". A ABDL atua nas discussões, mas também se engaja em programas pontuais de formação.

Embora algumas das entidades que participaram da pesquisa tenham mencionado atuar no Movimento Software Livre através de trabalhos específicos como tradução de textos, elaboração de conteúdos usando software livre e a organização de oficinas temáticas sobre o tema, a participação e divulgação do movimento através de listas de discussão e fóruns também é relevante. O MSL é um grande composto de idéias, ideologias e diferentes atores. Nesse contexto, as formas de atuar e militar também são as mais variadas possíveis, não seguindo um padrão exato. Desde que se esteja imerso nesse processo de cooperaçao e resistência global contra certos modelos impostos, pode-se estar cooperando com o movimento, pois ele também não exige uma presença fisica marcante. As relações, reinvidicações, interações e cooperação são muito mais mediadas pelo intelecto, devido ao auxílio da Internet do que por presença corporal.

\section{O que motiva uma ONG a atuar no Movimento Software Livre?}

Quando perguntamos ${ }^{22}$ para as ONGs quais questões as levariam ou levou-as a atuar no Movimento Software Livre, as alternativas dividiramse entre as razões sociais, políticas, ideológicas, econômicas, e outra alternativa. Conforme abaixo:

Tabela 5- Questões que levariam ou levaram uma entidade a atuar no MSL

\begin{tabular}{|l|c|}
\hline \multicolumn{1}{|c|}{ Questões motivadoras } & Número de respostas \\
\hline Sociais & 11 \\
\hline Políticas & 8 \\
\hline Ideológicas & 7 \\
\hline Econômicas & 7 \\
\hline Outra alternativa & 1 \\
\hline
\end{tabular}

Fonte: Dados da autora, organizado pela autora, 2008. 


\section{Gráfico 5}

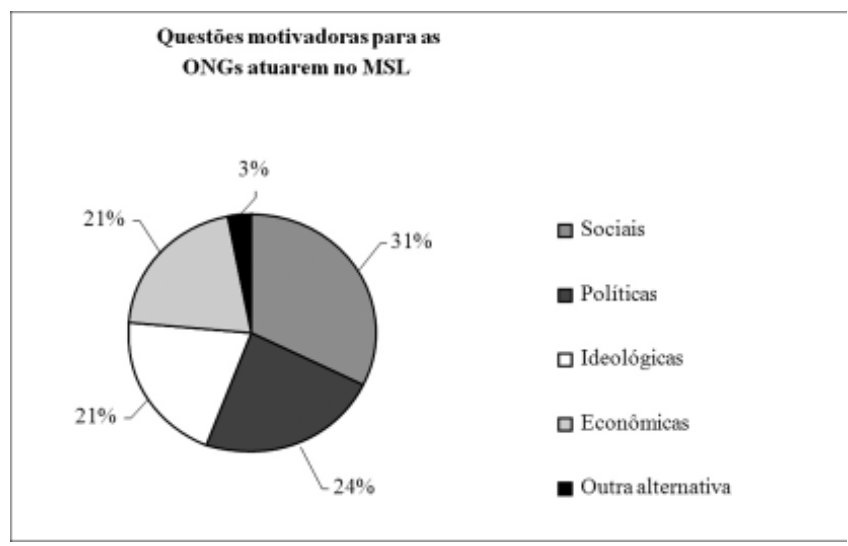

Fonte: Organizado pela autora, 2008.

Os dados expostos no gráfico 5 demonstram que a razão social (31\%) é a mais importante na hora de aderir ou militar no Movimento Software Livre. Seguida pela razão política (24\%). Logo após vem as razões ideológica e econômica empatadas (21\%). Alternativa outros apareceu em 3\% do total de escolhas. Observando os discursos de algumas entidades e comparando aos dados quantitativos, podemos concluir o grau de importância dessas escolhas.

A ASSESSOAR declara que o motivo para atuar no Movimento Software Livre é a razão social (31\%) por que "trabalhamos desde a nossa origem na perspectiva da socialização e da não privatização do conhecimento, desde as sementes aos softwares. Entendemos que a forma cooperada de produzir bens sociais, abertos, é que podem resolver efetivamente os problemas da exclusão, nas suas diversas modalidades”. A motivação política aparece em segundo lugar (24\%) das menções, isso demonstra que para uma entidade atuar no movimento o rompimento de tratados unilaterais determinados por certas empresas e países e um fator de muita importância. As alternativas econômica e ideológica seguem empatadas no terceiro lugar ( $21 \%$ cada uma) das respostas, o que nos leva a concluir que as duas motivações têm a mesma intensidade no momento da entidade atuar ou vir a atuar no Movimento Software Livre.

Apenas o Centro de Educação e Assessoramento Popular-CEAP, de Passo Fundo-RS assinalou a alternativa outros. O CEAP não usa software livre nem atua no Movimento Software Livre, mas ressalta que atuaria no movimento para a "qualificação da cidadania brasileira e mundial”, pois:

A história brasileira e mundial foi, e ainda é marcada por processos econômicos, sociais, culturais etc., extremamente desiguais e 
excludentes, onde a cidadania é permanentemente negada à grande parcela da população. Por outro lado, já foram construídas diversas alternativas frente a esta realidade no sentido de transformá-la. Por isso, o envolvimento no movimento tem uma motivação profundamente ética de buscar construir a cidadania para todos e todas, que ainda está longe de se realizar. Isso implica atualizar o significado do conceito cidadania no tempo e no espaço, compreendendo-a enquanto processo (CEAP: 2007).

Respostas como esta nos permite constatar e concluir que os sentidos do Movimento Software Livre vão muito além de motivações ou razões econômicas, educativas, ideológicas, políticas, tecnológicas e sociais, podendo ser de cunho ético, dentre outros. Uma entidade pode não usar software livre, nem atuar no Movimento Software Livre, porém isso não impede que ela eleja suas próprias questões ou motivações para cooperar ou militar no Movimento Software Livre.

Enfim, alguns de seus integrantes e simpatizantes são motivados pela utopia de igualdade econômica, outros pela socialização do conhecimento e da justiça social e outros contra a cultura vigente. Todos numa mesma direção, imersos num emaranhado de expectativas e apostas, que é: mostrar para a sociedade como é importante ter sua própria autonomia e independência, perante os sistemas econômicos vigentes, ou culturas dominantes que sufocam os saberes e as necessidades locais para defender seus interesses especulativos, impedindo-a de ter e criar suas próprias soluções, tanto em tecnologia como em autonomia socioeconômicas.

\section{Considerações finais}

Antes do advento do computador e das novas descobertas no campo tecnológico, as pessoas trabalhavam e estudavam usando tecnologias mais rudimentares. Com o surgimento dos computadores algumas práticas mudaram, as mesmas atividades que eram realizadas braçalmente e exigiam determinado tempo e grupo de pessoas, passaram a ser realizadas através destas novas máquinas e, em bem menos tempo.

Atualmente o uso dos computadores vem crescendo e a tendência da sociedade é se informatizar cada vez mais, mesmo que involuntariamente, pois quem não acompanhar esse processo estará automaticamente sendo excluído do sistema socioeconômico vigente, pela falta de capacitação, informação e dificuldade de comunicação. Hoje os PCs são utensílios básicos para produção industrial e intelectual/academia, onde servem como ferramenta na realização de pesquisas, textos, livros, relatórios, teses, dissertações, entre outros. Sem contar com inúmeras outras opções que o computador proporciona, como corretor e marcador de textos, além de programas que tabulam dados, constroem gráficos, fazem cálculos matemáticos usando fórmulas, uma infinidade de ferramentas ao alcance das mãos. 
Como afirma Giddens (1991: 77), estamos todos presos às experiências do cotidiano, cujos resultados, em um sentido genérico, são tão abertos quanto aqueles que afetam a humanidade como um todo. As experiências do cotidiano refletem o papel da tradição - em constante mutação - e, como também ocorre no plano global, devem ser consideradas no contexto do deslocamento e da reapropriação de especialidades, sob o impacto da invasão dos sistemas abstratos. A tecnologia, no significado geral da técnica, desempenha aqui o papel principal, na forma de tecnologia material da especializada expertise social.

No entanto nem todos têm acesso ou estão interessados na informatização, na tecnologia, mas precisam acima de tudo sobreviver, e a medida que a era técnica ou informatização avança, as pessoas perdem espaços, principalmente no mundo do trabalho e no que diz respeito as relações pessoais ou de contato pessoal (no sentido físico). Em países como o Brasil o processo tecnológico é lento e carece de um investimento financeiro que os indivíduos, as empresas e as entidades nem sempre têm à disposição. Em partes, esse alto custo da informatização se deve ao fato das máquinas serem importadas, pois o Brasil não tem uma indústria autônoma de hardware e outros periféricos de computador. Apesar de haver muitas indústrias que montam seus equipamentos no Brasil, a maior parte da matéria prima para esse processo de produção é importada, do Brasil se obtém a mão-de-obra barata. Além dos custos dos hardwares, somam-se o alto custo do desenvolvimento dos softwares e das suas licenças de uso.

Se não tiver alternativa, parte da sociedade civil irá aderir ao modelo imposto, sem questionar ou reclamar, apenas segue usando e pagando pelo seu usufruto, sem liberdade de escolha, uso ou prioridades. Cada fabricante, a seu modo, impõe o modelo desejado, não à maneira do cliente, mas a sua moda, deixando toda a sociedade refém do modelo tecnológico proposto, refém também das barreiras impostas pelo capital que o mercado dos softwares mobiliza e pelas barreiras políticas impostas através das formas de negociar as licenças ou direitos autorais dos softwares.

Mesmo com o alto custo dos computadores (máquina), principalmente dos softwares, seu uso é imprescindível. Muitas instituições e empresas não conseguem executar suas atividades sem essas ferramentas, assim como outros segmentos da sociedade civil, que está cada vez mais imersa nesse processo sociotécnico. Entretanto, algumas empresas, indivíduos e entidades estão saturadas com esses custos a mais no seu orçamento, e principalmente com a imposição da indústria de software, e buscam nos softwares livre uma outra alternativa, como é o caso das ONGs pesquisadas.

Nem todas as entidades que responderam ao questionário da pesquisa estão usando os softwares livre, mas há uma tendência muito grande para que isso aconteça. De 1993 até o momento atual houveram muitas adesões, o que demonstra que o seu uso vem crescendo e aumentando de lá para cá e que aos poucos essa idéia vai amadurecendo dentro da sociedade civil. Afinal, são quase 5 décadas de uso dos softwares proprietários contra 
apenas duas décadas e meia dos softwares livre, sem contar com o fato de que os softwares proprietários chegam à sociedade civil exatamente com a finalidade comercial, diferente dos softwares livre.

A maioria das pessoas é muito arraigada à cultura dos softwares da Microsoft, principalmente do Sistema Operacional Windows e seus aplicativos. Fora isso, às vezes há incompatibilidades entre os dois sistemas para receber determinados tipos de arquivos, pois as configurações dos softwares livre e proprietários nem sempre são correspondentes.

A sociedade está cada dia mais atrelada às inovações do campo tecnológico. Mas o fato da existência destas inovações não foi a questão central abordada neste artigo, e sim das relações da tecnologia com a sociedade, seus benefícios ou desvantagens. Mesmo ela sendo de fundamental importância hoje, a inclusão nesse processo é desigual devido a fatores econômicos e outros, como podemos ver entre as entidades analisadas.

Por fim, podemos concluir que grande parte do avanço do uso das plataformas livres no mundo se deve ao Movimento Software Livre, sem o qual a possibilidade da sociedade civil vir, a saber, o que é um programa livre seria muito remota. Provavelmente um número muito maior de pessoas e entidades não estariam informadas até hoje. Mesmo que a lógica da produção e difusão dos softwares livre seja cooperativa, sem divulgação e explicação não há como a sociedade civil entender os benefícios socioeconômicos, sociotécnicos e sociopolíticos que estão subscritos nessa nova tecnologia.

À medida que as tecnologias são democratizadas e usadas por alguns a favor de muitos, todos poderão tirar proveito, porém quando elas passam a ser de manutenção exclusiva e usadas para fins próprios, a comunidade tem pouco a ganhar com isso, e o que poderia ser de todos é privilégio de determinados grupos. A preocupação das entidades em contribuir com a eqüidade sócio-digital utilizando-se dos softwares livre e da sua lógica de produção e distribuição, demonstra o comprometimento de associações civis e movimentos sociais com a participação social de populações desfavorecidas em relação aos diferentes processos de comunicação e informação e pela inclusão social no mundo das novas tecnologias. As tecnologias da informação e comunicação podem ser instrumentos para promoção da igualdade de oportunidades, pois o conhecimento é uma excelente forma de intervir em diferentes situações, por isso, deve ser compartilhado por todos os indivíduos. 
Polis, Revista de la Universidad Bolivariana, Volumen 10, $N^{\circ}$ 28, 2011

\section{Notas}

* Este artigo faz parte de uma pesquisa de mestrado realizada em 2008 intitulada: Software livre e Movimento Software Livre: um estudo com as entidades associadas a ABONG.

${ }^{* *}$ Ao longo do texto usaremos o termo Organizações Não Governamentais - ONGs, para designar todas as entidades da sociedade civil sem fins lucrativo vinculadas a Associação Brasileira de Organizações Não Governamentais- ABONG.

${ }^{1}$ Desde que se tenha a máquina e a ligação com a Internet.

${ }^{2}$ Programas e sistemas operacionais copiados do Compact Disc original para outro qualquer, sendo que neles devem conter as senhas de instalação, pois sem as mesmas não há possibilidade de instalação.

${ }^{3}$ Serial, ou seja, número de série do produto que tem a mesma finalidade senha, que o programa pede ao ser instalado.

${ }^{4} \mathrm{O}$ uso do software proprietário, assim como de padrões patenteados, tem sido penoso para países como o Brasil e, em contrapartida, tem significado riqueza e poder para os países do hemisfério norte*. Um estudo do Banco Mundial chega a afirmar em 2001 que os "países industrializados são os principais beneficiários das regras da propriedade intelectual" (Pinheiro, W., 2003).

*Ver Story, A. Study on Intellectual Propriety, the Internet, and the Copyright (Study Paper 5). Commission on Intellectual Property Rights, 2002.

${ }^{5}$ Eric Paul Allman é um programador de computador que estando vinculado à Berkeley University of California desenvolveu o Sendemail (1970) e o seu precursor Delivermail (no início de 1980).

${ }^{6}$ Outras 22 entidades não responderam a essa pergunta, por não usarem softwares livre. ${ }^{7}$ Alguns (a maioria) voluntariamente.

${ }^{8}$ Entretanto, as entidades não mencionaram usar softwares livre como recurso de programação ou para fazer modificações tecnológicas. Adotam a questão tecnológica como uma ideologia política e como usuárias dos possíveis melhoramentos que a abertura dos softwares podem lhes proporcionar.

${ }^{9}$ Fundou a Free Software Foundation (FSF) em outubro de 1985.

${ }^{10}$ À medida que a sociedade se intera da existência de outras opções referente a softwares, poderá optar e decidir, mas se não conhecer outras, continuará inserida na lógica do sistema de comercialização e exploração tecnológico vigente, mesmo que arcar com esses custos e restrições seja um esforço demasiado.

${ }^{11}$ Referimos-nos aqui não ao Movimento Software Livre especificamente, mas toda a movimentação que envolve a construção, divulgação e uso desse tipo de software.

${ }^{12}$ Um exemplo é o Sistema Operacional Windows Vista, da Microsoft, lançado em 2007. Para poder comportar esse sistema, as máquinas devem ter uma ótima composição em 
hardware, caso contrário o sistema operacional não funciona, ou funciona precariamente. A maioria dos usuários não se adaptou, no entanto, nem sempre é possível trocar, pois os usuários não conseguem acessar os drivers de instalação dos dispositivos de hardwares. Disponível em: < http://pablolisboa-culturalivre.blogspot.com/2007/09/as-desvantagens-dosistema-proprietrio.html>.

${ }^{13}$ Sentença que faz o computador funcionar.

${ }^{14} \mathrm{O}$ termo comunidade aqui é usado para dar nome à sociedade como um todo, todos os seus membros.

${ }^{15}$ Um exemplo de facilidade*, rapidez e oportunidade são as compras via Internet, pois no ciberespaço não interessa a distância nem nacionalidade, todos podem oferecer e procurar mercadorias.

*Evidente que as transações comerciais através da Internet, assim como as presencias tem suas exigências.

${ }^{16}$ Cada ONGs ficou livre para assinalar quantas alternativas preferisse.

${ }^{17}$ Para realizar a participação efetivamente democrática de maneira interligada com outros movimentos é necessária uma maior articulação entre esses movimentos e um maior exercício democrático para se chegar a um consenso ou a um meio termo para que as conquistas tenham vultos maiores. Cabe comentar sobre as organizações voltadas para as questões relacionadas ao meio ambiente. Têm demandas similares, mas cada uma está focada em realizar os seus projetos. Os esforços para adequá-los a uma agenda maior ainda ficam restritos a eventos anuais e congressos. A participação e a articulação em conjunto por meio de estratégias de comunicação precisam trazer a mobilização, também, em conjunto, e com isso a efetiva participação democrática (Bona, 2007).

${ }^{18}$ Foi o caso do ISA e o Escritório Nacional da Associação Brasileira de ONGs, que tiveram conhecimento do Movimento Software Livre através de fóruns (Fórum Social MundialFSM e Fórum Internacional de Software Livre- FISL.

${ }^{19} \mathrm{O}$ contato pessoal pode ser feito de uma pessoa* a outra, de uma pessoa para muitas pessoas, de muitas pessoas para uma ou de muitas pessoas para muitas pessoas através da comunicação oral, podendo muitas vezes ser até de maneira interativa, onde o interlocutor tira as dúvidas com o locutor.

*A Associação Saúde Sem Limites, a Entidade ENDA Brasil e a sede do Movimento Tortura Nunca Mais, conheceram o movimento por intermédio de pessoas e amigos envolvidos com o tema.

${ }^{20}$ Revista Linux: é uma revista grátis bimestral em PDF. Os artigos vão desde artigos técnico-práticos a artigos teóricos e artigos filosóficos sobre o Open Source (www.revistalinux.com).

${ }^{21}$ Exceto alguns canais de TV educativos ou de cunho social, porém estes geralmente não pertencem ao que poderíamos chamar de "TV aberta”, na maioria das vezes pertencem a emissoras que os vende, e o rádio também é um veículo de informação não neutra que pode variar de acordo com os interesses dos seus proprietários. Caso a comunidade do Movimento 
Polis, Revista de la Universidad Bolivariana, Volumen 10, $N^{\circ}$ 28, 2011

Software Livre tenha alguns interessados ligados a esses dois meios de comunicação, o trabalho de divulgação poderá ser feito. Outra via pode ser por intermédio do Estado (programa Voz do Brasil) ou da sociedade civil organizada (Rádios comunitárias).

${ }^{22}$ Das 55 entidades que participaram da pesquisa, 39 delas não responderam a esse questionamento e 4 entidades escreveram não se aplica como resposta. 


\section{Bibliografia}

Abong (2006), ONGs no Brasil: Perfil das Associadas à ABONG. ABONG, São Paulo.

Almeida Filho, J. C. A. (2006), “Direito Eletrônico ou Direito da Informática?”, Revista Informática Pública, Belo Horizonte, v. 2, p. 11-18.

Benakouche, Tâmara, (2005), “Tecnologia é sociedade: contra a noção de impacto tecnológico”. In: Dias, Leila C. e Silveira Rogério L.L. da. (Org). Redes, sociedades e territórios, Santa Cruz do Sul - RS, Edunisc, p. 79106.

Bona, Nívea Canalli, Democracia e participação nos movimentos sociais: e a comunicação? Disponível em: http://www.intercom.org.br/papers/ nacionais/2007/resumos/R1340-2.pdf. Acesso em: 09/01/2008.

Brasil, Lei $n^{\circ}$. 9.609/98. Dispõe sobre a proteção de programas de computador Promulgada em 19/02/98, substitui a lei 7646/87, entrou em vigor na data de sua publicação. Disponível em: http://www.inpi.gov.br. Acesso em: 30/05/2008.

Borges, C., \& Geyer, C. F. R., Estratégias de governo para promover o desenvolvimento de software livre. Disponível em: http://www.inf.ufrgs.br/ clermont/estrategias_governo_sl.html, 2001. Acesso em: 02/05/ 2006.

Branco, Marcelo D’Elia, Software livre na administração pública brasileira. disponível em: http://www.softwarelivre.org/downloads/softwarelivrena administracaopublicabrasileira.pdf. Acesso em: 16/09/2008.

Conceição, Paulo Francisco da. (2005), Estudo de Caso de Migração para Software Livre do Laboratório da UEG Lavras. Monografia (Ciência da Computação)- Departamento de Ciências da Computação, Universidade Federal de Lavras, Minas Gerais.

Castells, Manuel (2004), A galáxia da internet: reflexões sobre a Internet, negócios e sociedade. Fundação Calouste Gulbenkian. Lisboa.

CETIC. Pesquisa sobre o uso das tecnologias da informação e da comunicação no Brasil (2006), Disponível em: http://www.cetic.br/tic/2006/ indicadores-2006.pdf. Acesso em: 20/01/2008.

CIPSGA. CIPSGA e sua luta para implantar os softwares livre no Brasil (2007), Entrevista de Djalma Valois ao site OLINUX em 02/12/2000. Disponível em: http://www.cipsga.org.br. Acesso em: 16/09/2007.

DEBIAN, Debian-BR: ajudando a universalização do Debian (2007), Disponível em: http://debian-br.cipsga.org.br. Acesso em: 04/12/2007. 
Doimo, Ana M.; Mitre, Mayra \& Maia, Rousely (2005), "Movimentos sociais, Internet e novos espaços públicos: o caso de DH net”. In: Dias, Leila C. e Silveira, Rogério L.L. da (Org), Redes, sociedades e territórios, Edunisc, Santa Cruz do Sul - RS, p. 107-130.

Franco, Marcelo Araújo (1997), Ensaio sobre as tecnologias digitais da inteligência. Papirus, Campina,. São Paulo.

Giddens, Anthony (1991), As conseqüências da modernidade. Unesp, São Paulo.

Guesser, Adauto H. (2005), Software livre e controvérsias tecnocientíficas: uma análise sociotécnica no Brasil e em Portugal. Dissertação (Mestrado em Sociologia Política)- Programa de Pós-Graduação em Sociologia Política, Universidade Federal de Santa Catarina, Florianópolis.

Lévy, Pierre (1998), A inteligência coletiva: por uma antropologia do ciberespaço. Loyola, São Paulo.

Maachado, Jorge Alberto S. (2007), “Ativismo em rede e conexões identitárias: novas perspectivas para os movimentos sociais”. Sociologias, n.18, p.248-285.

Marteleto, Regina M. (2001), Análise de redes sociais: aplicação nos estudos de transferência da informação. Ci. Inf., Brasília, v.30, n.1, p.71-81.

Moraes, Dênis de. (2001). O ativismo digital. Universidade Federal Fluminense, Brasil.

Open Source Initiative, The Open Source Definition, Disponível em: http:/ /www.opensource.org/docs/definition.html. Acesso em: 05/11/ 2007.

Ortensi, Mauricio Luiz, O que é Pirataria. Disponível em: http:// www.ortensi.com/info/pirataria_1.php. Acesso em: 20/11/2005.

Pinheiro, Walter, (2003), “A luta pelo software livre no Brasil”. In: Silveira, Sérgio Amadeo da. \& Cassiano, J., Software livre e inclusão digital. Conrad Editora do Brasil. São Paulo.

PROCEMPA, Porto Alegre. Disponível em: <http://linuxshop.ru/ linuxbegin/win-lin-soft-en/table.shtml>. Acesso em: 16/11/2003.

Projeto Software Livre RS, Projeto Software Livre RS. Disponível em: http:/ /www.softwarelivre.rs.gov.br. Acesso em: 16/06/2003.

Ribeiro, Gustavo Lins (2000), "Política cibercultural: ativismo digital a distância na comunidade transnacional imaginada-virtual”. In: Alvarez, S. 
E.; Dagnino, E. \& Escobar, A. (Org.), Cultura e movimentos sociais latino americanos: novas leituras. Ed. UFMG. Belo Horizonte.

Santos, Nilton Balis (2005), Estratégias de inclusão digital: a batalha das práticas culturais. Disponível em: http://www.gepicc.ufba.br/enlepicc/pdf/ NiltonBahlisDosSantos.pdf. Acesso em: 29/05/2007.

Scherer-Warren, Ilse (1996), Redes de movimentos sociais. Loyola. São Paulo.

Silveira, Sérgio Amadeo da (2003), “Inclusão digital, Software Livre e Globalização Contra-Hegemônica”. In: Silveira, Sérgio Amadeo da e Cassiano, J., Software livre e inclusão digital. Conrad Editora do Brasil. São Paulo.

Souza Santos, Boaventura (2002), A globalização e as ciências sociais. Cortez. São Paulo.

\section{Sites consultados}

http://www.openoffice.org.br

http://www.abong.org.br

http://www.fsf.org

http://psl-rs.softwarelivre.org

http://www.mmm.softwarelivre.org

http://www.revista-linux.com

http://pablolisboa-culturalivre.blogspot.com 


\section{Lista de siglas}

ABDL - Associação Brasileira para o Desenvolvimento de Lideranças ABIA - Associação Brasileira Interdisciplinar de AIDS ABONG - Associação Brasileira de Organizações Não Governamentais ABTH - Associação Brasileira Terra dos Homens ASSESOAR - Associação de Estudos, Orientação e Assistência Rural ASSL - Associação Saúde Sem Limites MTNM - Movimento Tortura Nunca Mais - PE CAAP - Centro de Assessoria à Autogestão Popular CAMPO - Centro de Assessoria ao Movimento Popular CR - Casa Renascer CPDD - Católicas Pelo Direito de Decidir CCLF - Centro de Cultura Luiz Freire CDHP - Centro de Direitos Humanos de Palmas CDDHP - Centro de Defesa dos Direitos Humanos de Petrópolis CDHMGB - Centro de Direitos Humanos Maria da Graça Braz CEAP - Centro de Educação e Assessoramento Popular CEB - Comunidades Eclesiais de Base CEBI - Centro de Estudos Bíblicos CEBRAP - Centro Brasileiro de Análise e Planejamento CEAP - Centro de Educação e Assessoria Popular CEPAC - Centro Piauiense de Ação Cultural CGGDH - Centro Gaspar Garcia de Direitos Humanos

CIEG - Centro Interdisciplinar de Estudos Grupais CIPÓ - Comunicação Interativa CMT - Casa da Mulher Trabalhadora CNMP - Centro Nordestino de Medicina Popular CRIAR BRASIL - Centro de Imprensa, Assessoria e Rádio CRIOLA

ECA - Estatuto da Criança e do Adolescente ECOA - Ecologia e Ação

EDISCA - Escola de Dança e Integração Social para Criança e Adolescente ELO - Ligação e Organização

ENDA BRASIL - Educação para o meio ambiente e o desenvolvimento ESPLAR - Centro de Pesquisa e Assessoria GAPA - Grupo de Apoio à Prevenção à AIDS

GARRA - Grupo de Apoio e de Resistência Rural e Ambiental GESTOS - Soro positividade, Comunicação e Gênero GIV - Grupo de Incentivo a Vida GMM - Grupo Mulher Maravilha GTP - Grupo Transas do Corpo GTP+ - Grupo de Trabalhos em Prevenção Posithivo IBASE - Instituto Brasileiro de Análises Sociais e Econômicas 
IBM - International Business Machines

IMENA - Instituto de Mulheres Negras do Amapá

INESC- Instituto de Estudos Socioeconômicos

INPI - Instituto Nacional da Propriedade Industrial

IRPAA - Instituto Regional da Pequena Agropecuária Apropriada

ISA - Instituto Socioambiental

ISER - Instituto de Estudos da Religião

ISPN - Instituto Sociedade, População e Natureza

GTLPL - Grupo de Teatro Loucas de Pedra Lilás

MIRIM-BRASIL - Movimento Infanto Juvenil de Reivindicação

MIT - Massachusetts Institute of Technology

MOC - Movimento de Organização Comunitária

MTNM - Movimento Tortura Nunca Mais - PE

NPAE - Nova Pesquisa e Assessoria em Educação

ONG - Organizações Não Governamentais

PACS - Instituto Políticas Alternativas Para o Cone Sul

PC - Personal Computer

PRECAVVIDA - Centro de Prevenção e Recuperação O Caminho, a Verdade e a Vida

RS - Rio Grande do Sul

SC - Santa Catarina

SEDUP - Serviço de Educação Popular

SOS Corpo - Instituto Feminista para a Democracia

SOS Mata Atlântica

TI - Tecnologia da Informação

Recibido 11-01-2011

Aceptado 03-03-2011 